\title{
Abscesso cerebral por Nocardia sp em paciente imunossuprimido
}

\author{
Brain abscess by Nocardia sp in \\ immunocompromised patient
}

\begin{abstract}
Cristina Hueb Barata ${ }^{1}$, Darci Alvarenga Gomes Oliveira ${ }^{2}$, Arnaldo Lopes Colombo ${ }^{3}$ e Carlos Alberto Pires Pereira ${ }^{3}$
\end{abstract}

\begin{abstract}
Resumo Paciente portadora de anemia hemolítica autoimune e púrpura trombocitopênica idiopática (Síndrome de Evans) em uso de terapia imunossupressora (predinisona e azatioprina), desenvolveu quadro de abscesso cerebral não responsivo a 23 dias de terapia antimicrobiana. O diagnóstico de nocardiose foi possível após coleta de material de abscesso peribulbar e observação deste material por período superior há uma semana.
\end{abstract}

Palavras-chaves: Nocardiose. Doenças oportunistas em imunossuprimido. Nocardia sp.

Abstract Pacient with autoimmune haemolytic anaemia and thrombocytopenic purpura (Evans Syndrome), treated with immunosuppressive therapy (prednisone and azathioprine) developed brain abscess unresponsive to antimicrobial therapy, in spite of its 23 days duration. Diagnosis could be possible after recover secretion of peribulbar abscess and maintenance of this material over seven days in incubation.

Key-words: Opportunistic disease. Nocardiosis. Nocardia sp.

A nocardiose é uma doença eminentemente oportunista, acometendo pacientes portadores de imunossupressão sistêmica, particularmente, da imunidade celular. Apresentamos um paciente portador de Síndrome de Evans em uso de medicamentos imunossupressores, que desenvolveu quadro de nocardiose disseminada após sessão de pulsoterapia para tratamento da doença de base.

\section{RELATO DE CASO}

Paciente feminina, 40 anos, parda, casada, do lar, com diagnóstico de anemia hemolítica autoimune e púrpura trombocitopênica idiopática (Sindrome de Evans). Há 16 anos em uso de prednisona e azatioprina. Em fevereiro de 1999, foi submetida à pulsoterapia com metil-prednisolona por apresentar intensa artralgia. Nódulos subcutâneos sugestivos de eritema nodoso e 14.000 plaquetas $/ \mathrm{mm}+$. Após 30 dias da pulsoterapia evoluiu com quadro pulmonar grave, sendo internada em outro hospital para tratamento de pneumonia com antimicrobianos. Durante a internação apresentou cefaléia intensa, edema palpebral unilateral com discreta ptose à esquerda, rigidez de nuca terminal (+/4+) e vômitos acompanhados de intensa apatia e adinamia. Diagnosticado abscesso cerebral por tomografia computadorizada de crânio (Figura 1). No $11^{\circ}$ dia de antibioticoterapia com Clindamicina e Cefepime. Como não apresentasse melhora clínica, laboratorial ou radiológica do abscesso, a paciente foi transferida para o Hospital Escola da

\footnotetext{
1. Doenças Infecciosas e Parasitárias da Faculdade de Medicina do Triângulo Mineiro. 2. Hematologia da Faculdade de Medicina do Triângulo Mineiro. 3. Doenças Infecciosas e Parasitárias da Universidade Federal de São Paulo (UNIFESP/EPM).

Endereço para correspondência: Dra. Cristina Hueb Barata. Disciplina de Doenças Infecciosas e Parasitárias/FMTM. Av. Getúlio Guaritá s/n, 38025-000 Uberaba, MG, Brasil.

Fax: 5534 3318-5274

e-mail: chueb@zaz.com.br

Recebido para publicação em 10/3/00.
} 


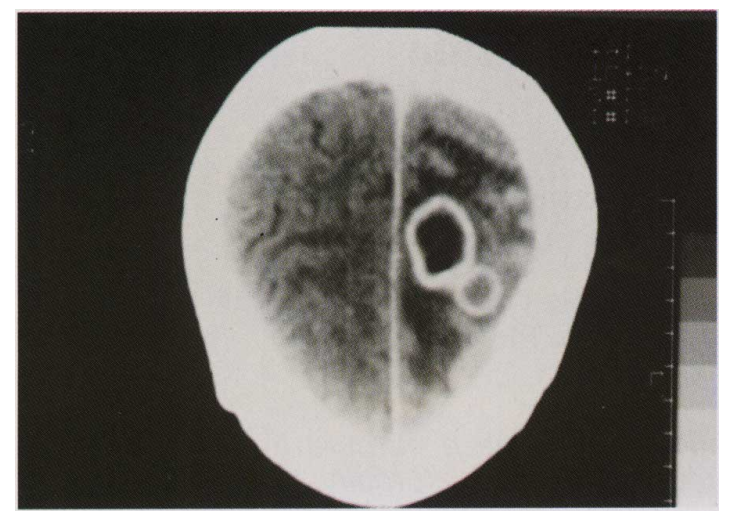

Figura 1 - Tomografia de crânio com abscesso cerebral antes do tratamento.

Faculdade de Medicina do Triângulo Mineiro (FMTM) para ser submetida à cirurgia estereotáxica.

As culturas do material da lesão não apresentaram crescimento bacteriano e a pesquisa de células neoplásicas foi negativa. Mesmo após este procedimento a paciente permaneceu com quadro neurológico grave e evoluindo com lesão oftálmica à esquerda com abscesso retiniano e celulite peri-orbitária. No 23음 dia de antibioticoterapia foi aventada a possibilidade de processo fúngico ou por bactéria multirresistente (Staphylococcus coagulase negativo). Prescritos Vancomicina, Imipinem/Cilastatina e Anfotericina B.

Houve melhora gradativa do quadro neurológico e regressão da celulite peri-orbitária, inclusive com remissão da dor ocular que só cedia com opiáceos. Dez dias após o início deste esquema terapêutico amplo, surgiu abscesso peribulbar em olho esquerdo, sendo colhido material deste local e também do humor aquoso. As culturas apresentaram no final de oito dias crescimento de colônias de aspecto algodonoso mas de coloração alaranjada, que foi identificada após avaliação da micromorfologia em coloração apropriada como Nocardia sp (Figura 2).

A medicação foi mudada para sulfametoxazoltrimetropim em altas doses, mantida por 10

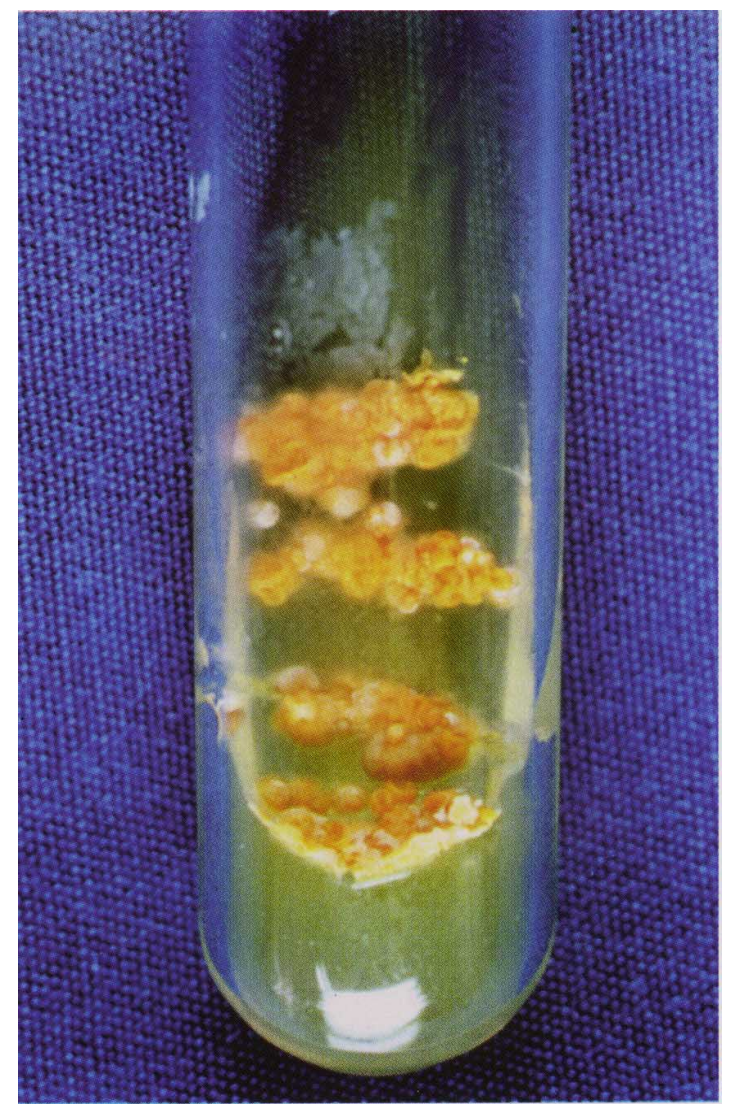

Figura 2 - Colônias de Nocardia sp em secreção do abscesso peribulbar.

meses até a paciente ficar com dose mínima de corticosteróides $(10 \mathrm{mg} / \mathrm{dia})$ e retirada do imunossupressor.

A paciente evoluiu bem, com recuperação das suas funções motoras e mentais. Desapareceram as lesões nodulares subcutâneas e estabilizouse o quadro hematológico. Embora tenha ocorrido perda do globo ocular à esquerda, as lesões em CT de crânio de controle, após seis meses de terapêutica específica, haviam desaparecido.

\section{DISCUSSÃO}

Nocardiose é uma infecção localizada ou disseminada causada por actinomicetos aeróbicos presentes no solo, mais comumente adquiridos através do trato respiratório. Normalmente as infecções por Nocardia sp são exógenas (causada por organismos que não fazem parte da microbiota humana normal) ${ }^{19}$. O envolvimento pulmonar em humanos ${ }^{5}$ é autolimitado ou subclínico, com formas agudas, subagudas, ou crônicas simulando tuberculose 
ou infecção fúngica ou neoplasia. Nesta paciente, não nos foi possível determinar o grau de comprometimento pulmonar. A nocardiose causa doença broncopulmonar em pacientes imunocomprometidos, com alta taxa de disseminação hematogênica para o SNC e pele. Os pacientes de alto risco são aqueles portadores de deficiência de células $T$ decorrente de doenças tais como leucemia, SIDA/AIDS ou, como em nosso caso, em uso de terapia imunossupressora ou situações que requerem uso prolongado de corticóides $^{356}$. O SNC está infectado em um terço de todos os casos, podendo predominar as manifestações neste sistema mas com disseminação sistêmica. Aproximadamente 45\% dos pacientes com nocardiose sistêmica têm infecção do SNC, e os pulmões representam a fonte primária mais comum. Nocardia sp invade o cérebro silenciosamente e pode persistir em latência por vários meses até anos quando surgem as primeiras manifestações ${ }^{267}$. A apresentação pode ser aguda, rapidamente progressiva, mas apresentações de início insidioso e gradual com várias manifestações podem também ocorrer. Enquanto o abscesso é o achado patológico mais freqüente, como evidenciado nesta paciente, algumas vezes há relato de áreas com inflamação difusa ${ }^{1}$.

A Nocardia sp também causa infecções oculares em indivíduos tanto imunocomprometidos como imunocompetentes .Nestes tendo como fator de risco a assepsia inadequada das lentes de contato ${ }^{4}$.

Convém enfatizar que os pacientes usando altas doses de corticóides e/ou outros imunossupressores podem se infectar por agentes menos comuns e que a investigação para estes germes deve fazer parte da rotina em pacientes que não respondem aos esquemas convencionais de antibioticoterapia.

O comprometimento cutâneo pode ser primário ou decorrente da disseminação pulmonar. Nossa paciente apresentava-se com nódulos subcutâneos que desapareceram com a medicação específica para nocardiose, corroborando a hipótese de que também fossem decorrentes da infecção por Nocardia sp.
Deve-se aventar o diagnóstico de Nocardia quando o paciente é imunocomprometido e além da pneumonia (ás vezes com cavitação), houver evidência de disseminação para o SNC e tecidos subcutâneos.

A Nocardia $s p$ pode crescer em meios de culturas laboratoriais pouco seletivos, entretanto seu isolamento requer no mínimo uma semana de incubação. No presente caso, a hipótese de microorganismos pouco usual só foi possível quando as culturas para os agentes infecciosos mais prevalentes foram descartadas e optou-se por manter este material incubado por um período superior a sete dias. Suas colônias têm morfologia variada desde formas secas até algodonosas e variando do branco ao laranja ${ }^{58}$. Vários actinomicetos podem causar micetoma mas nas Américas o mais freqüente é a $N$. brasiliensis. No presente caso não foi possível a identificação da espécie da Nocardia. São conhecidas 10 espécies de Nocardia, sendo difícil sua identificação baseada nas propriedades fenotípicas. As espécies mais freqüentemente encontradas no homem são: Nocardia asteroides, $N$. brasilienses, N. otitidiscaviarume N. farcinica ${ }^{8}$. O complexo N. asteroides é responsável por $90 \%$ das infecções humanas ${ }^{579}$. Um terço dos pacientes com infecção por $N$. asteroides apresentam envolvimento do SNC com formação de abscessos único ou múltiplos ${ }^{12}$.

O tratamento das infecções por Nocardia sp baseia-se na associação do uso de antimicrobianos adequados e intervenção cirúrgica. Sulfonamidas são os medicamentos de escolha, embora os aminoglicosídeos (tobramicina e amicacina) e alguns novos betalactâmicos apresentem boa atividade in vitro ${ }^{3}$, assim como o Imipenem/Cilastatina, que provavelmente foi o responsável pela melhora inicial da paciente após a cirurgia cerebral. A antibioticoterapia deve se estender por seis ou mais semanas, com boa resposta nos pacientes com infecção localizada e pior prognóstico nos imunocomprometidos com doença disseminada ${ }^{56}$.

\section{REFERÊNCIAS BIBLIOGRÁFICAS}

1. Barnicoat MJ, Wierzbicki AS, Norman PM. Cerebral nocardiosis in immunosuppressed patients: five cases. Quarterly Journal of Medicine 72:689-698, 1989.

2. Curry WA. Human nocardiosis. A clinical review with selected case reports. Archives of Internal Medicine 140:818-826, 1980.
3. Khardori N, Shawar R, Gupta R, Rosenbaum B, Rolston K. In vitro antimicrobial susceptibilities of Nocardia sp. Antimicrobial Agents and Chemotherapy 37:882-884, 1993.

4. Kelly SJ, Waghorn D, Ademokun A. Nocardiosis in an immunocompromised patient - an unusual presentation. Journal of Infection 22:269-271, 1991. 
5. Lerner PI. Disease due to higher bacteria. In: Mandell GL, Douglas RG, Bennett JE (eds) Principles and Practice of Infectious Diseases. $4^{\text {th }}$ edition. New York: Churchill Livingstone, p. 2273-2280, 1995.

6. Lerner IP. Nocardiosis Clinical Infectious Diseases 22:891-905, 1996.

7. Mahgoub ES. Agents of mycetoma. In: Mandell GL, Douglas RG, Bennett JE (eds) Douglas and Bennett's principles and practice of infectious diseases, $4^{\text {th }}$ edition. Churchill Livingstone, New York, vol 2. p. 2327-2330, 1995.

8. McNeil M, Brown J. The medically important aerobic actinomycetes: epidemiology and microbiology. Clinical Microbiology Review 7:357-417, 1994.

9. Murray PR, Rosenthal KS, Kobayashi GS, Pfaller MA. Medical Microbiology $3^{\text {rd }}$ edition. Missouri: Mosby-Year Book, p. 313-316, 1994. 